\title{
Time Lag and Nutrient Storage Effects in the Transient Growth Response of Chlamydomonas reinhardii in Nitrogen-limited Batch and Continuous Culture
}

\author{
By A. CUNNINGHAM AND P. MAAS \\ Department of Applied Physics, Strathclyde University, \\ 107 Rottenrow, Glasgow G4 0NG
}

(Received 1 August 1977; revised 7 October 1977)

\begin{abstract}
Chlamydomonas reinhardii populations in nitrite-limited chemostat culture exhibited damped oscillations in cell number following sharp changes in dilution rate. These oscillations had a period of about $70 \mathrm{~h}$ and damped out after not more than two clearly observable cycles. Residual nitrogen in the culture medium during these cycles remained very low (less than $1 \mu \mathrm{mol} \mathrm{N}{ }^{-1}$ ). The oscillations were apparently caused by the presence of a complex delay of two distinct physiological components in the relationship between cell division rate and environmental limiting nutrient concentration.
\end{abstract}

\section{INTRODUCTION}

The growth dynamics of populations of unicellular algae in rapidly fluctuating environments may be more complex than a simple consideration of their steady state behaviour suggests. Williams $(1965,1970)$, working with nitrogen-limited chemostat cultures of Chlorella pyrenoidosa and Selenastrum gracile, claimed that rapid dilution rate changes were followed by damped oscillations in cell number. However, the frequency of sampling in his experiment was too low to permit unambiguous interpretation of the data as he counted cells only once per day when dealing with oscillations with a $50 \mathrm{~h}$ period. In similar experiments with Isochrysis galbana cultures, Caperon (1969) found overshoots in cell number, but no oscillations, following temporary cessations in flow rate. These experiments also suffered from a low sampling frequency. Oscillations in population density in chemostat culture were mentioned incidentally by Droop (1966) and Pickett (1974). There is a need, therefore, for more accurate studies of the growth of microalgal cultures in rapidly changing conditions. In particular, relevant experimental variables must be measured at a sampling frequency high enough to resolve the fine detail of any oscillatory behaviour that might occur. This paper describes experiments of this type carried out on the green flagellate Chlamydomonas reinhardii under nitrite-limited conditions.

\section{METHODS}

Experiments were carried out on strain 32a of Chlamydomonas reinhardii Dangeard (from the NERC Culture Collection of Algae and Protozoa, Cambridge). This strain comprises one half of a heterothallic pair, and the cells consequently reproduce vegetatively in pure culture. The cultures were grown in a modified version of Bold's basal medium, in which growth was nitrogen-limited up to a concentration of $400 \mu \mathrm{mol} \mathrm{N} 1^{-1}$. The medium contained (mg l-1): $\mathrm{CaCl}_{2} .6 \mathrm{H}_{2} \mathrm{O}, 25 ; \mathrm{MgSO}_{4} .7 \mathrm{H}_{2} \mathrm{O}, 25 ; \mathrm{KH}_{2} \mathrm{PO}_{4}, 500 ; \mathrm{NaCl}, 250 ; \mathrm{FeSO}_{4}$. $7 \mathrm{H}_{2} \mathrm{O}, 5 ; \mathrm{MnCl}_{2} .4 \mathrm{H}_{2} \mathrm{O}, 15 ; \mathrm{MoO}_{3}, 0.7 ; \mathrm{CuSO}_{4} .5 \mathrm{H}_{2} \mathrm{O}, 0.0075 ; \mathrm{ZnSO}_{4} .7 \mathrm{H}_{2} \mathrm{O}, 0.08 ; \mathrm{CoCl}_{2} .6 \mathrm{H}_{2} \mathrm{O}, 0.005 ;$ EDTA, 7.5; and $\mathrm{NaNO}_{2}$, as limiting nutrient, at $250 \mu \mathrm{mol} \mathrm{N}{ }^{-1}$ in batch cultures and $50 \mu \mathrm{mol} \mathrm{N}{ }^{-1}$ in chemostat cultures. (Batch cultures had an initial volume of 31 which was reduced to about 21 in the course of sampling. Chemostat cultures were held at 1 litre.) All cultures were grown in spherical glass reaction vessels, immersed in a constant temperature bath maintained at $17 \pm 0 \cdot 1^{\circ} \mathrm{C}$. Illumination was provided by banks of 


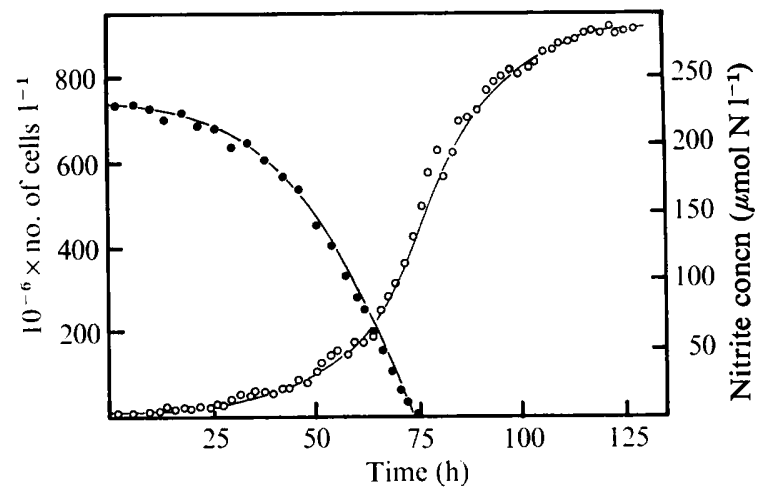

Fig. 1. Batch culture of Chlamydomonas reinhardii: $\bigcirc$, cell numbers; $\bullet$, residual nitrite in medium.

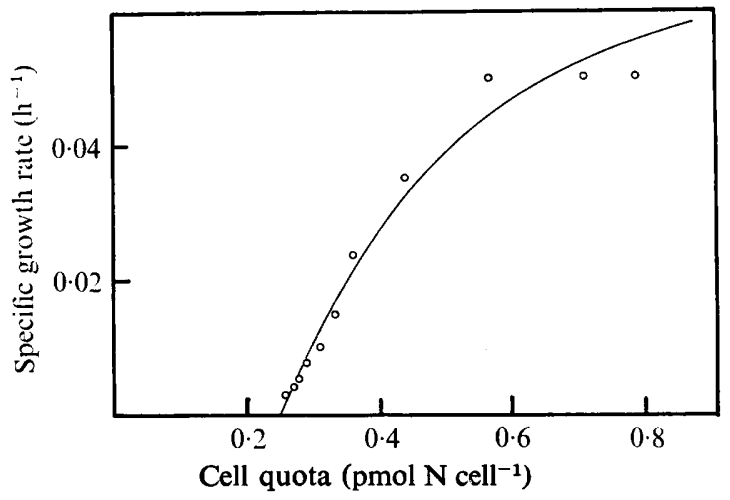

Fig. 2. Relationship between cell quota and specific growth rate during the batch culture of Fig. 1 .

The curve represents the best fit of equation 3 , see text, to the data.

warm white fluorescent lights, producing an incident light intensity, measured inside the culture vessel, of $400 \mu \mathrm{W} \mathrm{cm}{ }^{-2}$. Stirring, at 60 rev. $\mathrm{min}^{-1}$, was via a chevron-sealed gland (Sovirel glassware; V. A. Howe). Vigorous aeration maintained a positive air pressure inside the growth chamber and helped prevent contamination. Culture samples were routinely examined by phase-contrast microscopy, and any experimental runs suspected of contamination were discarded. In continuous culture experiments (for further details, see Cunningham, 1976), medium was pumped into the growth chamber via a peristaltic pump; the variation in daily flow rate was less than $5 \%$.

Samples $(7 \mathrm{ml})$ were withdrawn automatically every hour and preserved in tubes containing $0.2 \mathrm{ml} 40 \%$ $(\mathrm{w} / \mathrm{v})$ formaldehyde solution. This rate of sampling did not disturb the normal operation of the chemostat since steady states were observed before and after the induced transient periods. Cells were counted using a model $\mathrm{Zb}$ Coulter counter, and alternate samples were filtered and assayed for residual nitrite using the method of Strickland \& Parsons (1972). As formaldehyde interferes with the assay, appropriate calibration curves had to be constructed. Usually, cell counts had a standard deviation of $0.5 \%$ of the mean figure of many counts, and nitrite assays a standard deviation of $2 \%$. The lowest detectable nitrogen concentration was $0.75 \mu \mathrm{mol} \mathrm{N}{ }^{-1}$.

\section{RESULTS}

\section{Batch culture}

In a typical Chlamydomonas batch culture (Fig. 1), the population density followed the familiar sigmoid curve while the limiting nutrient fell to an undetectable level. Significantly, cell division continued for some time after exhaustion of the limiting nutrient, eventually yielding almost twice as many cells as at the moment of nitrite exhaustion.

There is considerable evidence which suggests that the specific growth rate of microalgae is controlled, not by the concentration of limiting nutrient in the environment, but by the 
amount of that nutrient within the cells (Droop, 1968; Fuhs, 1969; Davies, 1970; Caperon \& Meyer, 1972; Paasche, 1973). Our data (Fig. 1) suggest this also holds for Chlamydomonas reinhardii under nitrite limitation. The idea may be expressed quantitatively by relating the cell quota $(Q)$, defined as the average limiting nutrient content per cell, to the specific growth rate (Fig. 2). Assuming that all the nutrient disappearing from the medium is taken up by the cells,

$$
Q=\frac{S_{\mathrm{i}}-S}{x}
$$

where $S_{\mathrm{i}}$ is the concentration of nitrite in the medium at the start of the experiment, $S$ is the residual nitrite concentration at a given time, and $x$ is the population density at that time. Specific growth rate $(\mu)$ is given by

$$
\mu=\frac{1}{x} \cdot \frac{\mathrm{d} x}{\mathrm{~d} t}
$$

The relationship between $Q$ and $\mu$ in batch culture (Fig. 2) is a type of saturation curve, fitted by the expression

$$
\mu=\frac{\mu_{\max } \cdot\left(Q-Q_{0}\right)}{K_{\mathrm{q}}+\left(Q-Q_{0}\right)}
$$

where $Q_{0}$ is the minimum cell quota occurring at zero growth rate. The parameters $\mu_{\max }$, the value approached by $\mu$ as $Q$ tends to infinity, and $K_{\mathrm{q}}$, the half saturation constant, are best understood by analogy with Michaelis-Menten enzyme kinetics. The use of equation 3 was first suggested by Caperon \& Meyer (1972). Values of the parameters for the curve drawn in Fig. 2 are $Q_{0}=0.25 \mathrm{pmol} \mathrm{N}$ cell $^{-1}, K_{\mathrm{q}}=0.36 \mathrm{pmol} \mathrm{N}$ cell ${ }^{-1}$ and $\mu_{\max }=0.094 \mathrm{~h}^{-1}$.

\section{Continuous culture}

Two types of non-steady state chemostat growth situations were investigated. In two experiments, cultures inoculated into the chemostat were allowed to reach the plateau phase of batch culture growth before the nutrient pump was switched on. In three additional runs, cultures established in steady state continuous growth were subjected to a rapid increase in pumping rate. In all experiments, the disturbed populations reached a final steady state condition by means of a series of heavily damped oscillations. These oscillations damped out after no more than two observable cycles, and had a period in the range 40 to $200 \mathrm{~h}$. There was no obvious trend in this period with regard to the growth rate at the final steady state. None of the oscillations recorded look like the product of a single harmonic oscillator but the data are not precise enough to warrant speculation on this point. Figure 3 shows the response of growth to a sudden shift in dilution rate from 0.023 to $0.034 \mathrm{~h}^{-1}$ in a typical experiment. As the amount of residual limiting nutrient did not rise above the minimum detectable concentration, virtually all the nitrite supplied to the cultures must have been taken up by the cells, and so the oscillations in population density were not driven by large-scale fluctuations in environmental nutrient concentration.

The data of Fig. 3 may be further analysed in terms of cell quota and specific growth rate (Fig. 4). The total absorption of residual limiting nutrient by the cells makes it possible to calculate the mean cell quota during transients from the same expression as that used for batch cultures (equation 1) by substituting the reservoir concentration of limiting nutrient $\left(S_{\mathrm{r}}\right)$ for $S_{\mathrm{i}}$. To calculate the specific growth rate, the loss of cells via the overflow must be taken into account, so that

$$
\mu=\frac{1}{x} \cdot \frac{\mathrm{d} x}{\mathrm{~d} t}+D
$$

where $D$ is the dilution rate.

Cell quota and specific growth rate oscillate with about the same period during the transient stage, but there is a phase lag between the two variables (Fig. 4). While this lag is probably 


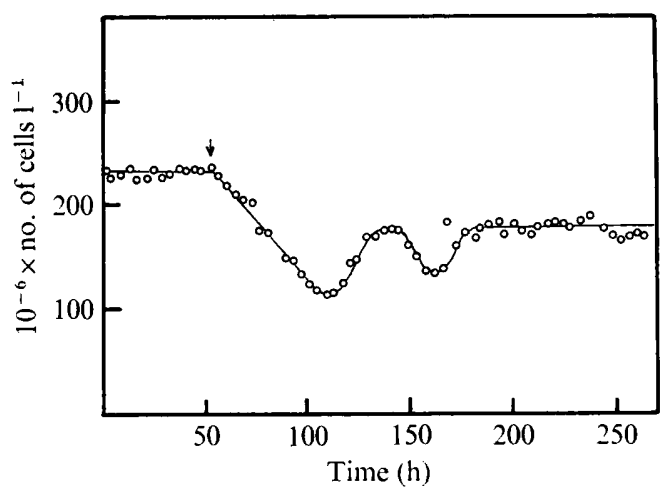

Fig. 3. Transient growth behaviour of Chlamydomonas reinhardii in a chemostat. The dilution rate was increased from 0.023 to $0.034 \mathrm{~h}^{-1}$ at the time indicated by the arrow.

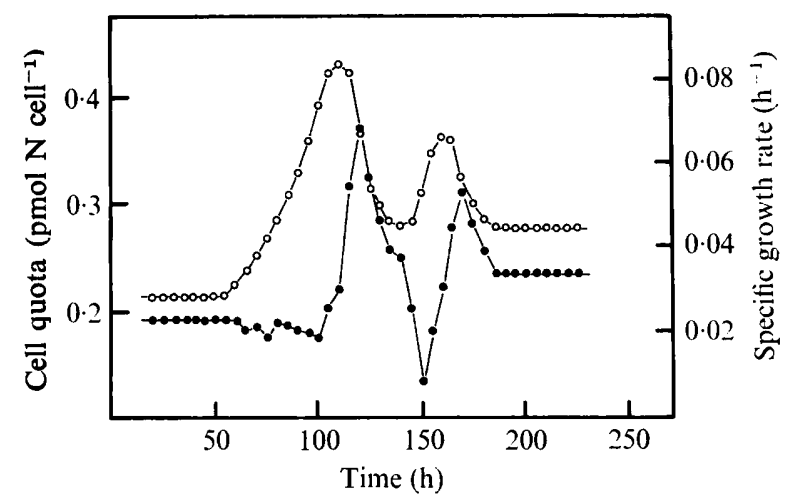

Fig. 4. Variation of cell quota $(O)$ and specific growth rate $(\bullet)$ during the step experiment of Fig. 3.

a complex function of the physiological state of the cells in the culture, it can be described to a first approximation by a simple discrete time lag in the response of specific growth rate to cell quota fluctuations. Equation 3 therefore becomes modified:

$$
\mu=\frac{\mu_{\max } \cdot\left(Q_{t-\tau}-Q_{0}\right)}{K_{\mathbf{q}}+\left(Q_{t-\tau}-Q_{0}\right)}
$$

where $Q_{t-\tau}$ is the cell quota occurring $\tau$ hours before the instant of calculation of $\mu$. The data available suggest that $\tau$ has a value of about $10 \mathrm{~h}$.

These results, obtained at a sampling rate of 12 times that of previous studies, seem to establish that the oscillatory growth behaviour suggested by Williams (1965) for other species does indeed occur in Chlamydomonas reinhardii. They also provide direct evidence for the discrete lag in population growth response postulated on indirect grounds by Caperon (1969).

\section{DISCUSSION}

Following rapid shifts in dilution rate, Chlamydomonas populations in nitrite-limited chemostat culture exhibit oscillations in cell number which could be generated by two quite different physiological mechanisms. Either the shifts in dilution rate could physiologically shock the population, sufficient to induce a degree of synchrony in the timing of cell division, with subsequent oscillations then being the automatic result of the altered age-structure of the population. Alternatively, the oscillations could arise from a partial uncoupling of the system. controlling cell division from changes in environmental limiting nutrient con- 
centration, causing the system to 'hunt' in its attempts to follow sudden alterations in dilution rate. The existing evidence does not indicate which of these two mechanisms is most likely, but, in view of the mathematical complexity of chemostat models incorporating agestructure effects (Hansche, 1969), it seems desirable to examine the 'uncoupling' hypothesis before invoking the more complex phenomenon of synchronization. Two factors contributing to this uncoupling have been observed experimentally. Firstly, cell division rate is apparently controlled by the quantity of nitrogen inside the cells and, at high growth rates, considerable intracellular storage of nitrogen may occur. Secondly, there is a time lag between fluctuations in this intracellular nutrient content and the corresponding fluctuations in cell division rate. Despite the proliferation of mathematical models of the growth of algae in continuous culture (Williams, 1967; Caperon, 1969; Caperon \& Meyer, 1972; Grenney, Bella \& Curl, 1973; Droop; 1974, 1975), oscillations of the type shown in Fig. 3 do not appear to be predicted by any existing theoretical treatment of the system. There is a need, therefore, for a simple model of microalgal growth which incorporates both nutrient storage and a discrete time lag in the form of a growth function of the type quoted in equation 5. In particular, it ought to be possible to use such a model to assess the relative importance of the two distinct uncoupling factors mentioned above in contributing to the oscillatory behaviour of the population. Attempts to formulate and analyse modified versions of the Monod model of the steady state growth of bacteria (Monod, 1950) with these objectives in mind are currently in progress.

\section{REFERENCES}

CAPERon, J. (1969). Time lag in population growth response of Isochrysis galbana to a variable nitrate environment. Ecology 50, 188-192.

Caperon, J. \& Meyer, J. (1972). Nitrogen limited growth of marine phytoplankton II. Uptake kinetics and their role in nutrient limited growth of phytoplankton. Deep Sea Research 19, 619-632.

Cunningham, A. (1976). Transient growth dynamics of Chlamydomonas reinhardii populations in nitritelimited continuous culture. Ph.D. thesis, University of Strathclyde, Glasgow.

DAvies, A. G. (1970). Iron, chelation, and the growth of marine phytoplankton I. Growth kinetics and chlorophyll production in cultures of the euryhaline flagellate Dunalliela tertiolecta under iron-limited conditions. Journal of the Marine Biological Association of the United Kingdom 50, 65-86.

Droop, M. R. (1966). Vitamin $\mathbf{B}_{12}$ and marine ecology III. An experiment with a chemostat. Journal of the Marine Biological Association of the United Kingdom 46, 659-671.

Droop, M. R. (1968). Vitamin $\mathbf{B}_{12}$ and marine ecology IV. The kinetics of uptake, growth, and inhibition in Monochrysis lutheri. Journal of the Marine Biological Association of the United Kingdom 48, 689-733.

Droop, M. R. (1974). The nutrient status of algal cells in continuous culture. Journal of the Marine Biological Association of the United Kingdom 54, $825-855$.

Droop, M. R. (1975). The nutrient status of algal cells in batch culture. Journal of the Marine Biological Association of the United Kingdom 55, 541-555.

FuHs, G. W. (1969). Phosphorus content and rate of growth in the diatoms Cyclotella nana and Thalassiosira fluviatilis. Journal of Phycology 5, 312-321.

Grenney, W. J., Bella, D. A. \& Curl, JR, H. C. (1973). A mathematical model of the nutrient dynamics of phytoplankton in a nitrate-limited environment. Biotechnology and Bioengineering 15, 331-358.

HANSChe, P. E. (1969). A theoretical basis for the entrainment of chemostat populations. Journal of Theoretical Biology 24, 335-350.

MonoD, J. (1950). La technique de culture continue: theorie et applications. Annales de l'Institut Pasteur 79, 390-401.

PAASCHE, E. (1973). Silicon and the ecology of marine plankton diatoms I. Thalassiosira pseudomona Hade and Heimdal (Cyclotella nana Hustedt) grown in a chemostat with silicate as the limiting nutrient. Marine Biology 19, 117-126.

PiCketT, J. M. (1974). Growth of Chlorella in a nitrate-limited chemostat. Plant Physiology 55, 223-225.

Strickland, J. D. H. \& Parsons, T. R. (1972). $A$ Practical Handbook of Seawater Analysis, 2nd edn, Bulletin of the Fisheries Research Board of Canada, no. 167, pp. 79-82.

Williams, F. M. (1965). Population growth and regulation in continuously cultured algae. Ph.D. thesis, Yale University.

Wir.liams, F. M. (1967). A model of cell growth dynamics. Journal of Theoretical Biology 15, 190207.

Williams, F. M. (1970). Dynamics of microbial populations. In Systems Analysis and Simulation in Ecology, vol. II, pp. 197-267. Edited by B. C. Patten. New York: Academic Press. 